\title{
Bronchodilator efficacy of tiotropium in patients with mild to moderate COPD
}

\section{*Gunnar Johansson a , Anne Lindbergb, Kerstin Rombergc, Lars Nordström ${ }^{\mathrm{d}}$, Fronke Gerkene, Annika Roquet ${ }^{d}$}

\author{
${ }^{a}$ Associate Professor, Nyby Healthcare Centre and Department of Public Health and Caring Sciences, Uppsala University, Uppsala, Sweden \\ b Senior Consultant, The OLIN Studies and Division of Respiratory M edicine, Sunderby Hospital, Luleå, Sweden \\ ${ }^{c}$ General Practioner, Näset Healthcare Centre, Höllviken, Sweden \\ ${ }^{d}$ Clinical monitor, Boehringer Ingelheim AB, Stockholm, Sweden \\ e Statistician, Boehringer Ingelheim Pharma GmbH \& Co, Ingelheim, Germany
}

Originally submitted 21st December 2007; resubmitted 6th March 2008; revised version received 29th April 2008;

accepted 7th M ay 2008; online 6th June 2008

\begin{abstract}
Aims: Evaluation of tiotropium efficacy in patients with mild chronic obstructive pulmonarydisease (COPD) defined by the 2003 Swedish Society of Respiratory Medicine guidelines (post-bronchodilator $\mathrm{FEV}_{1} / \mathrm{FVC}<70 \%$; FEV $1 \geq 60 \%$ predicted).

Methods: In this 12-week, randomised, double-blind, placebo-controlled study of tiotropium 18 mcg once daily versus placebo, respiratory function was assessed on Days 1, 15 and 85 (baseline: pre-dose Day 1).

Results: Mean \pm SD baseline $\mathrm{FEV}_{1}$ (\% predicted) was 73.4 \pm 12.5 (tiotropium, $n=107$; placebo, $\mathrm{n}=117$ ). Tiotropium significantly improved change from baseline in area under the curve from pre-dose to 2 hours post-dose ( $\mathrm{AUC}_{0-2} \mathrm{~h}$ ) FEV 1 versus placebo, by $166 \pm 26 \mathrm{~mL}$ (mean \pm SE) at study end $(p<0.0001)$. With tiotropium, there were significant increases in the change in AUC $0-2 \mathrm{~h} F \mathrm{FC}$ versus baseline, and trough $\mathrm{FEV}_{1}$ and $\mathrm{FVC}$, versus placebo, on all test days $(\mathrm{p}<0.01)$. Adverse event rates were similar.

Conclusion: Compared with placebo, tiotropium mproved lung function in patients with mild COPD.

(C) 2008 General Practice Airways Group. All rights reserved

G Johansson, et al. Prim Care Resp L 2008, 17(3): 169-175.

doi:10.3132/pcrj.2008.00037
\end{abstract}

Keyw ords chronic obstructive pulmonary disease, mild, moderate, tiotropium

\section{Introduction}

Chronic obstructive pulmonary disease (COPD) is a progressive debilitating disease that leads to significant morbidity. However, it is usually not diagnosed until patients are symptomatic and the disease is moderately advanced. ${ }^{1} \mathrm{An}$ epidemiological research program in northern Sweden, the OLIN studies, reported that the prevalence of COPD was $14.3 \%$, with most patients $(57 \%)$ having mild disease according to the Global Initiative for Chronic Obstructive Lung Disease (GOLD) criteria (post-bronchodilator forced expiratory volume in one second $\left[\mathrm{FEV}_{1}\right] /$ forced vital capacity [FVC] $<70 \%, \mathrm{FEV}_{1} \geq 80 \%$ predicted). ${ }^{2,3}$ Although $70 \%$ of these subjects were symptomatic, only $5 \%$ had a relevant prior diagnosis. ${ }^{2}$ Furthermore, all subjects with severe or very severe COPD (6\% of diagnosed cases) were symptomatic, but only $50 \%$ of them reported a physician diagnosis of COPD.

Bronchodilators provide symptomatic management of COPD, administered as-needed or regularly. How ever, optimal timing for initiating maintenance therapy is not clearly defined. Whilst the decline in $\mathrm{FEV}_{1}$ over time is the standard measure of COPD disease progression, other outcomes including breathlessness, activity levels, exacerbations and health-related quality of life (HRQL) also worsen. ${ }^{4}$ Therefore, it is imperative that COPD patients receive appropriate treatment, including preventive interventions, as early as possible. Tiotropium (Boehringer Ingelheim, Ingelheim am

\footnotetext{
* Corresponding author: Department of Public Health and Caring Sciences, Family Medicine and Epidemiology, Science Park, 75185 Uppsala, Sweden. Telephone: +46186113427 Fax: +46 18511657 E-mail: gunnar.johansson@pubcare.uu.se
} 
Rhein, Germany) is a once-daily anticholinergic agent that works through prolonged $\mathrm{M}_{3}$-receptor blockade. Tiotropium has consistently been shown to have a beneficial effect on lung function and patient-centred outcomes in COPD patients. ${ }^{5-9}$ Retrospective analysis of earlier studies suggests that tiotropium may benefit patients with mild COPD (GOLD criteria). ${ }^{10}$ However, to date, no prospective studies have been performed specifically in mild COPD.

In Sweden in 2003, mild COPD was defined as $\mathrm{FEV}_{1} / \mathrm{FVC}$ $<70 \%$ and $\mathrm{FEV}_{1} \geq 60 \%$ predicted according to the Swedish Society of Respiratory Medicine. ${ }^{11}$ This definition corresponded to the 1997 British Thoracic Society (BTS) criteria for mild COPD ( $\mathrm{FEV}_{1} 60-80 \%$ predicted $)^{12}$ and was comparable with the 1995 American Thoracic Society (ATS) guidelines for stage 1 "mild" COPD (FEV $1 \geq 50 \%$ predicted). ${ }^{13}$ In Sweden, mild COPD is now defined as $\mathrm{FEV}_{1} / \mathrm{FVC}<70 \%$ and $\mathrm{FEV}_{1} 50-79 \%$ predicted. ${ }^{14}$ In 2003, Swedish guidelines contained no standard treatment recommendations for patients with mild COPD. ${ }^{11}$

The aim of this study was to assess the effects of oncedaily tiotropium $18 \mathrm{mcg}$ on lung function, clinical symptoms and HRQL in patients with mild COPD according to 2003 Swedish guidelines (mild to moderate COPD according to GOLD guidelines).

\section{Method \\ Study population}

Inclusion criteria were: outpatients aged $\geq 40$ years old with $\mathrm{a}$ COPD diagnosis of mild COPD by 2003 swedish guidelines (post-bronchodilator $\mathrm{FEV}_{1} / \mathrm{FVC}<70 \%$ and $\mathrm{EEV}_{1} \geq 60 \%$ predicted); smoking history of $\geq 10$ pack-years; and a Medical Research Council (MRC) dyspnoea score of $\geq 2$. Exclusion criteria were: history of asthma, allergic rhinitis or atopy; blood eosinophil count $\geq 600 / \mathrm{mm}^{3}$; recent lower respiratory tract infection or any exacerbation (within the previous six weeks); recent history of myocardial infarction (within the previous six months); unstable cardiac arrhythmia; regular use of oxygen therapy; use of oral or inhaled steroids (within the previous three months); and significant diseases other than COPD.

\section{Study design}

This was a 12-week, randomised, double-blind, parallelgroup, multicentre study (protocol number 205.281). An Institutional Review Board approved the study protocol and all participants gave written informed consent. The primary end-point was change in $\mathrm{FEV}_{1}$ area under the curve from predose (zero time) to 2 hours post-dose $\left(A \cup \mathrm{C}_{0-2} \mathrm{~h}\right.$ ), from baseline to 12 weeks. Other end-points were $\mathrm{FEV}_{1}$ and FVC trough responses, use of rescue medication, and adverse events. Dyspnoea and HRQL were assessed using questionnaires.

\section{Study methods}

Following a screening visit, patients underwent a 2 week run-in. After a further assessment on Day 1, eligible patients were randomised 1:1 to receive tiotropium $18 \mathrm{mcg}$ or placebo once daily in the morning for 12 weeks, delivered using the HandiHaler ${ }^{\otimes}$ device (Boehringer Ingelheim). Assessments were conducted on Days 1, 15 (2 weeks) and 85 (12 weeks). Baseline was the pre-dose measurement on Day 1 . Patients were permitted salbutamol metered-dose inhaler as rescue medication, as-needed, for acute symptom relief, with an 8-hour washout period before spirometry. Use of short-acting anticholinergics, $\beta_{2}$-agonists (other than rescue medication), oral or inhaled corticosteroids, or theophylline, was not permitted. However, to treat COPD exacerbations, investigators could prescribe antibiotics and oral corticosteroids (for $\leq 2$ weeks) or theophylline (for $\leq 7$ days). Spirometry was postponed for 1 to 2 weeks after treatment for an exacerbation.

Spirometry was performed at screening and on Days 1,15 and $85 . \mathrm{FEV}_{1}$ and FVC were recorded 10 minutes before, and 0.5, 1 and 2 hours after dosing. FEV 1 and FVC trough responses were the pre-dose values on Days 15 and 85. All spirometric tests were conducted in triplicate, and the highest measurements were used for analysis. The equipment and methodologies used fulfilled ATS (1994) or European Respiratory Society (1993) standards. ${ }^{15,16}$

Questionnaires assessing dyspnoea and HRQL were administered at the start and end of the study. Dyspnoea was evaluated using the baseline dyspnoea index $(\mathrm{BDI})^{17}$ and the M RC dyspnoea scale. ${ }^{18}$ The BDI has three domains (functional impairment, magnitude of task and magnitude of effort), each with scores from 0 (very severe impairment) to 4 (no impairment). Scores are summed to determine the BDI focal score $(0-12)$. Patients also defined their perceived dyspnoea using the M RC dyspnoea scale (grade 0 [no breathlessness] to 5 [too breathless to leave the house or breathless when dressing or undressing]). As an exploratory measure, the BDI was also used for assessment on Day 85 instead of using the transitional dyspnoea index (TDI). ${ }^{17} \mathrm{HRQL}$ was evaluated using the generic European Quality of Life Questionnaire, the EuroQol (EQ-5D), 19,20 consisting of the EQ-5D Visual Analogue Scale (VAS) and the EQ-5D index. The VAS has a rating scale of 0 to $10 \mathrm{~cm}$, taken as $0-100 \%(0 \%$, death/worst possible health; $100 \%$, best possible health). The EQ-5D index is a 5item questionnaire (mobility, self-care, usual activity, pain/discomfort and anxiety/depression). For each item, the patient selects one from three descriptive health states (from good to poor) and the number/percentage of patients selecting each state is recorded.

Patients recorded the daily number of rescue medication doses used. Adverse events, including COPD exacerbations, were recorded. 


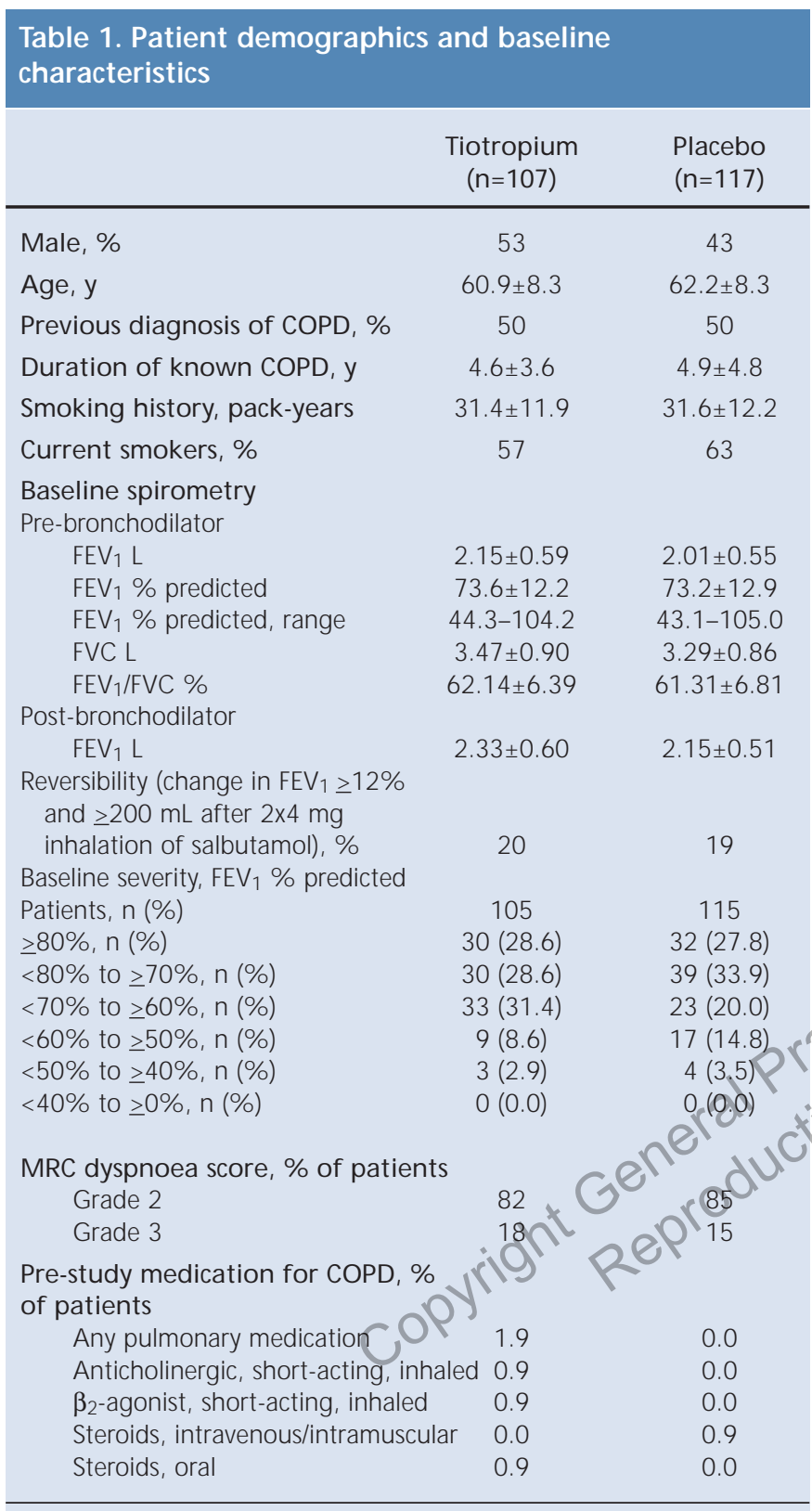

Data are mean $\pm S D$ unless otherwise stated. Post-bronchodilator lung function was assessed 20 minutes after the inhalation of salbutamol.

\section{Data analysis}

One hundred patients per randomised treatment group were required to provide $80 \%$ power to detect a between-group difference of $120 \mathrm{~mL}$ in the primary end-point (change in $\mathrm{AUC}_{0-2} \mathrm{~h} \mathrm{FEV}_{1}$ versus baseline after 12 weeks' treatment) two-sided t-test at a $5 \%$ significance level. The sample size was based on data from a previous tiotropium study with similar elements. ${ }^{21}$ Efficacy was measured in all randomised patients who received study medication and had a baseline measurement and at least one valid post-treatment measurement (full analysis population). The safety population was all randomised patients who received $\geq 1$ treatment dose.
Analysis of covariance with terms for treatment and pooled centre was used for all continuous end-points, with baseline data as covariates. The number of doses of rescue medication was summarised as weekly means, expressed as doses/day. Summary data are presented as adjusted mean \pm standard error (SE) unless stated otherwise. For missing spirometric data, the last observation was carried forward, except when patients discontinued due to worsening COPD, where the least favourable data before discontinuation were carried forward.

\section{Results}

A total of 224 patients were randomised to tiotropium $(n=107)$ and placebo $(n=117)$. The study was conducted from March 2004 to July 2005 at 27 centres in Sweden. The two treatment groups had comparable $\mathrm{FEV}_{1}$ and $\%$ predicted $\mathrm{FEV}_{1}$ values at baseline (Table 1). $20 \%$ and $19 \%$ of the patients in the tiotropium and placebo group, respectively, had significant reversibility $(>12 \%$ reversibility and $>200 \mathrm{ml}$ ). All patients had an $\mathrm{MBC}$ dyspnoea score of $\geq 2$. A total of 62 $(28.2 \%), 151(68.6 \%), 7(3.2 \%)$, and $0(0.0 \%)$ patients were defined as having GOLD stage I, II, III, and IV COPD, respectively.

\section{Spirometry}

The change in $\mathrm{AUC}_{0-2} \mathrm{~h} \mathrm{FEV}$ from baseline to Day 85 was significantly improved with tiotropium compared with Oplacebo $(157 \pm 19 \mathrm{~mL}$ versus $-9 \pm 18 \mathrm{~mL}$; difference $166 \pm 26$ $\mathrm{mL}, \mathrm{p}<0.0001$ ) - Figure 1. Significant increases in $\mathrm{AUC}_{0-2} \mathrm{~h}$ $\mathrm{FEV}_{1}$ responses were also observed in the tiotropium group compared with placebo on Day 1 (by $74 \pm 15 \mathrm{~mL}, \mathrm{p}<0.0001$ ) and Day $15(172 \pm 22 \mathrm{~mL}, \mathrm{p}<0.0001)$ - Figure 1 .

Compared with placebo, patients had a significant bronchodilator response (increase in $\mathrm{FEV}_{1}$ ) within 30 minutes after the first dose of tiotropium (Day 1 difference in change from pre-dose: $35 \pm 18 \mathrm{~mL}, \mathrm{p}<0.05)$. $\mathrm{FEV}_{1}$ responses were significantly improved compared with baseline at all timepoints on all test days with tiotropium versus placebo (all $\mathrm{p}<0.05$ ) - see Figure 2. After two weeks, the trough $\mathrm{FEV}_{1}$ response was significantly greater by $109 \pm 20 \mathrm{~mL}$ with tiotropium compared with placebo $(p<0.0001)$. At study end, trough $\mathrm{FEV}_{1}$ was $74 \pm 23 \mathrm{~mL}$ above baseline for patients receiving tiotropium, while it was $45 \pm 22 \mathrm{~mL}$ below baseline in those receiving placebo (between group difference: $118 \pm 31 \mathrm{~mL}, \mathrm{p}<0.001)$. In addition, significant improvements in $\mathrm{AUC}_{0-2} \mathrm{~h}$ and trough $\mathrm{FEV}_{1} \%$ predicted were observed in the tiotropium group ( $p<0.01$, for all time-points).

The pattern of the $\mathrm{FEV}_{1}$ results was also seen for the FVC results. Compared with placebo-treated patients, tiotropium patients had statistically significant improvements in $A U C_{0-2} \mathrm{~h}$ FVC response on Days $1(89 \pm 27 \mathrm{~mL}, \mathrm{p}<0.01), 15(182 \pm 37$ $\mathrm{mL}, \mathrm{p}<0.0001)$ and $85(160 \pm 43 \mathrm{~mL}, \mathrm{p}<0.001)$ - see Figure 3 . 
Figure 1. Adjusted mean FEV 1 AUC $0-2$ h change in response versus baseline follow ing tiotropium or placebo on Days 1, 15 and 85.

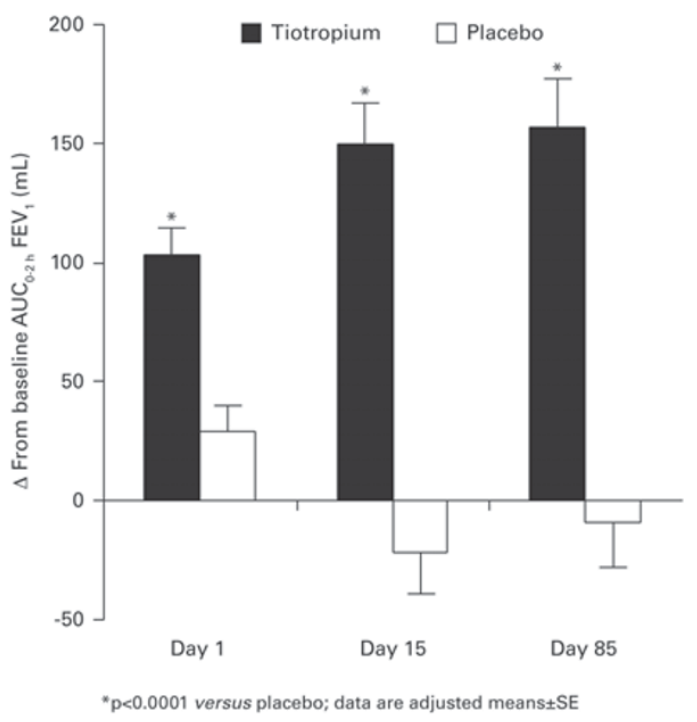

Figure 2. Adjusted mean $F E V_{1}$ change from baseline before and during the 2 hours following tiotropium or placebo on Days 1, 15 and 85.

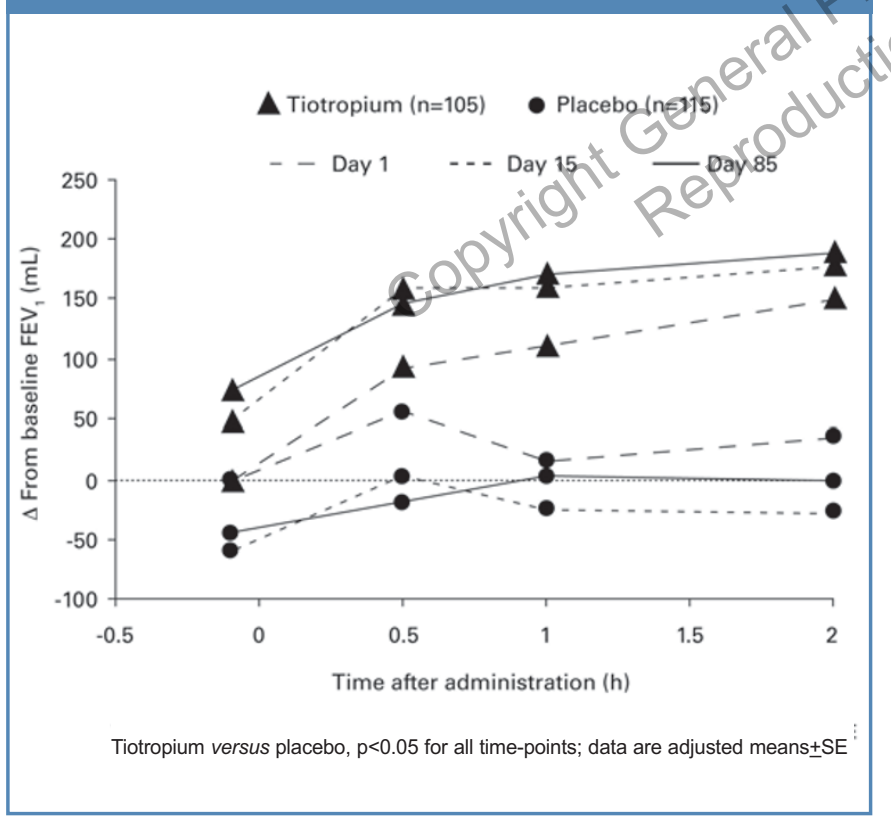

Statistically significant improvements in trough FVC were observed in the tiotropium group on Days $15(178 \pm 36 \mathrm{~mL}$, $p<0.0001)$ and $85(187 \pm 50 \mathrm{~mL}, p<0.001)$ (Figure 4).

\section{Use of rescue medication}

Use of rescue salbutamol was low before randomisation (tiotropium $0.71 \pm 0.05$ doses/day; placebo $0.76 \pm 0.05$
Figure 3. Adjusted mean FVC $A_{U} C_{0-2} h$ change from baseline following tiotropium or placebo on Days 1, 15 and 85 .

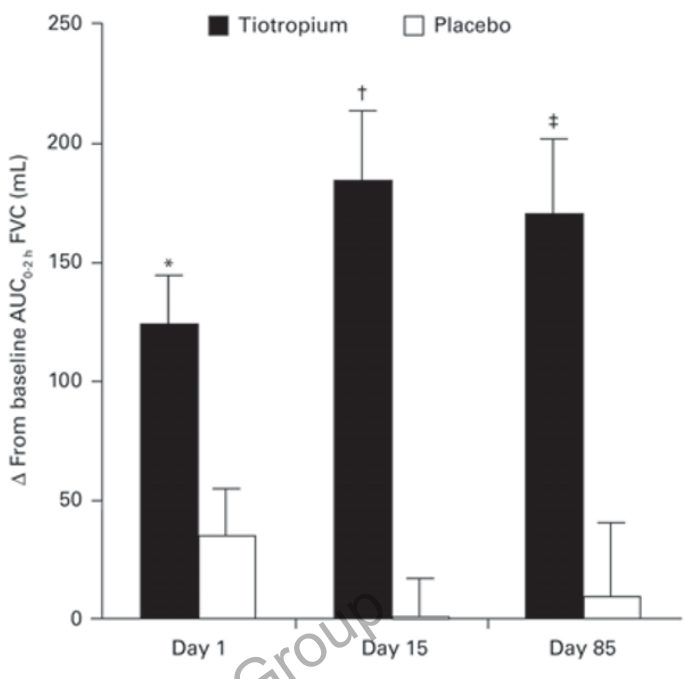

'p<0.01, 'p<0.001, $p<0.0001$ versus placebo; data are adjusted means \pm SE 12

Figure 4. Adjusted mean FVC change from baseline before and during the 2 hours following tiotropium or placebo on Days 1, 15 and 85.

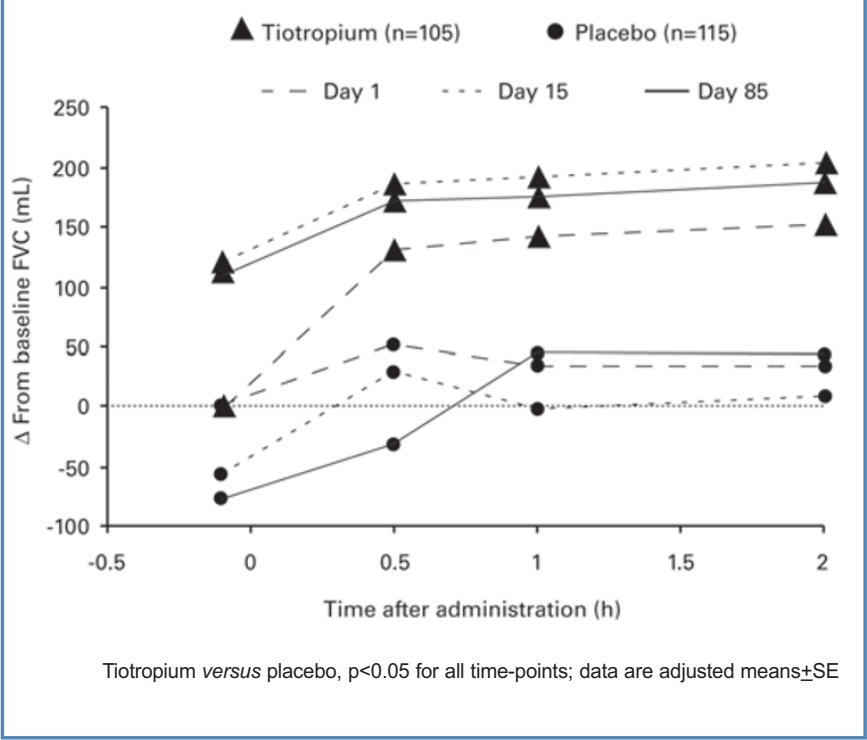

doses/day) and decreased during the study (Week 12: tiotropium $0.23 \pm 0.05$ doses/day; placebo $0.29 \pm 0.05$ doses/day). Patients receiving tiotropium self-administered significantly fewer doses per day compared with placebo during Weeks 1 to 5, and also Week 9 (treatment differences of 0.17 to 0.23 doses/day; $p<0.05$ ). 


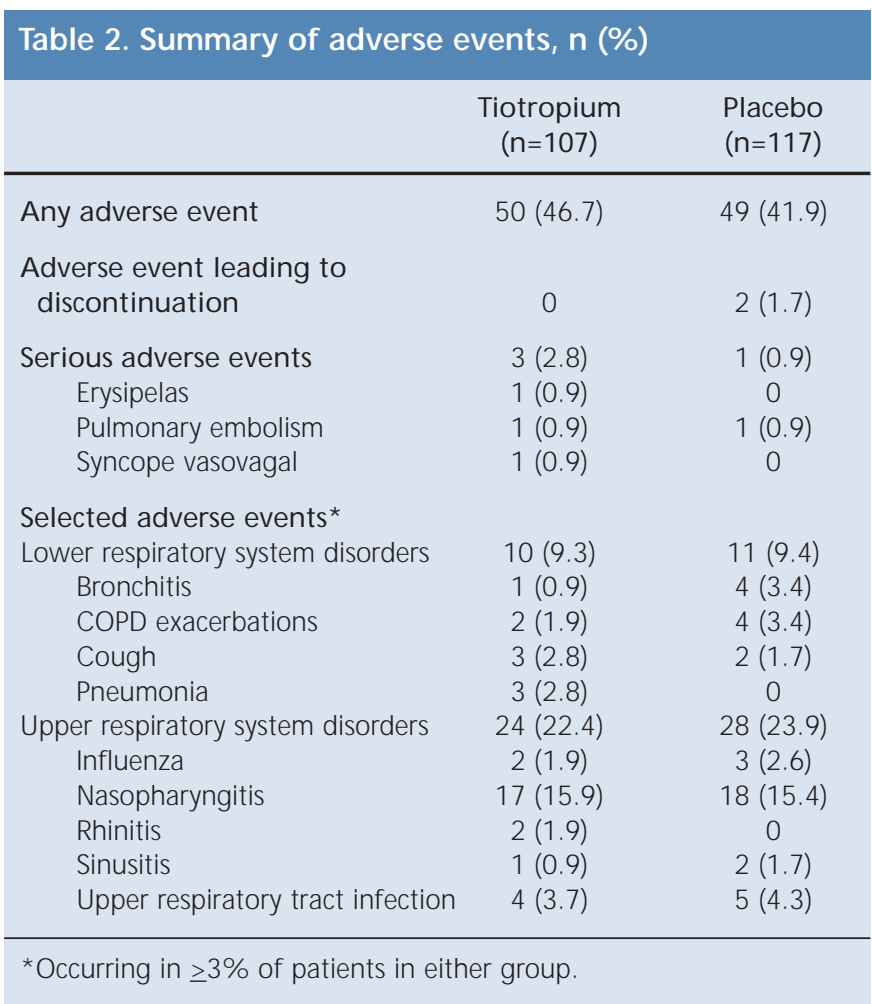

\section{Dyspnoea and generic HRQL}

In patients with mild COPD, patients in both groups experienced only minor activity-related dyspnoea and their generic HRQL was only moderately impaired at baseline and study end. There was no significant difference between the tiotropium and placebo groups for BDI focal score at study end $(8.57 \pm 0.11$ versus $8.45 \pm 0.11)$. At study end, similar proportions of patients in the two groups had an improvement, deterioration oro change in MRC dyspnoea score, the EQ-5D VAS scores were the same, and there was no significant difference between groups for EQ-5D total score (tiotropium $0.83 \pm 0.01$; placebo $0.85 \pm 0.01$ ). Although the majority of patients in both groups (tiotropium versus placebo) had no problems with self-care $(99.0 \%$ versus $99.1 \%)$, walking $(82.9 \%$ versus $87.0 \%)$ or performing usual activities $(89.5 \%$ versus $88.7 \%)$, in the EQ-5D sub-scale items, a sizeable proportion of patients experienced moderate pain/discomfort (47.6\% versus $49.6 \%)$, or moderate anxiety or depression (25.7\% versus $31.3 \%$ ) (all tiotropium versus placebo).

\section{Adverse events}

Similar percentages of patients experienced an adverse event (see Table 2). A serious adverse event was experienced by $2.8 \%$ of tiotropium and $0.9 \%$ of placebo patients. However, none was considered to be treatment-related. No tiotropium patients and two placebo patients $(1.7 \%)$ discontinued due to adverse events. Two tiotropium patients $(1.9 \%)$ and four placebo patients (3.4\%) experienced an exacerbation.

\section{Discussion}

International guidelines recommend the use of long-acting anticholinergic agents, such as tiotropium, as maintenance therapy in patients with moderate-to-very severe COPD (GOLD guidelines). ${ }^{3}$ This study investigated the effects of 12 weeks' treatment with tiotropium $18 \mathrm{mcg}$ once daily on lung function in patients with mild COPD as defined by 2003 Swedish guidelines (GOLD definition; mild to moderate COPD)., ${ }^{3,11}$ The baseline mean $\mathrm{FEV}_{1}$ was comparable between groups. Half the patients were undiagnosed with COPD prior to study entry and $<2 \%$ were receiving any pre-study medication for COPD. At study end, tiotropium-treated patients had significantly improved lung function versus baseline and versus placebo. These improvements were apparent 30 minutes after the first dose, were maintained over 24 hours, and were sustained during the study.

To enable comparison of this trial with others that use GOLD guidelines, this study population had mild to moderate COPD as defined by GOLD criteria. ${ }^{3}$ The lower limit of the 2003 Swedish guidelines for mild COPD falls within the GOLD COPD guidelines for moderate COPD (FEV $1 \geq 50-80 \%$ predicted), while GOLD guidelines for mild COPD require an $\mathrm{FEV}_{1} \geq 80 \%$. ${ }^{3,11} \mathrm{Cu}$ rrent Swedish guidelines retain a similar classification of disease severity for COPD as in 2003 (mild COPD.OFEV $150-79 \%$ predicted), ${ }_{14}^{14}$ which is equivalent to moderate COPD according to GOLD guidelines. Using the GOLD categorisation, $28.2 \%, 68.6 \%$, and $3.2 \%$ of patients had mild, moderate, and severe COPD, respectively. The severity of the patient group investigated here contrasts with that of previously-conducted tiotropium trials. A pooled analysis of the baseline characteristics of the patients from 24 previous tiotropium trials reveals that only $0.2 \%$ of patients from a total of 24 trials were defined as GOLD stage I, compared with $26.9 \%, 49.0 \%$, and $23.9 \%$ of patients with moderate, severe, and very severe COPD, respectively, defined using the GOLD criteria (Boehringer Ingelheim, data on file). A unique element of this study is that it was specifically designed to assess the efficacy of tiotropium in this oftenoverlooked group of patients with mild COPD.

These findings confirm observations from retrospective studies that tiotropium is effective in patients with milder COPD. In 1639 patients with different severities of COPD, ${ }^{21} 12$ weeks' treatment with tiotropium significantly improved trough and 2-hour post-dose $\mathrm{FEV}_{1}$, with the most pronounced changes observed in 531 patients with mild disease (ATS criteria: pre-dose $\mathrm{FEV}_{1} \geq 50-70 \%$ predicted). A post hoc analysis of two 1-year trials of maintenance treatment-naive COPD patients revealed that, in the subset of 20 patients with mild COPD (GOLD guidelines) who received tiotropium, trough, peak and mean $\mathrm{FEV}_{1}$ and FVC significantly improved from baseline. ${ }^{10}$ The magnitude of the 
improvements compared with placebo at Week 12 in this present trial were similar to those observed by Beeh et al. ${ }^{21}$

Improving lung function is essential for the relief of COPD symptoms, especially breathlessness. The BDI and TDI focal scores evaluate activity-related dyspnoea and change in dyspnoea, respectively, using ratings of the major items affecting development of dyspnoea. ${ }^{17}$ Large-scale trials have shown that tiotropium improves the TDI focal score compared with placebo or ipratropium in patients with moderate to severe disease. ${ }^{5-7}$ Since patients in this study were expected to have only mild activity-related dyspnoea at baseline, a useful change in TDI after 12 weeks was not expected. While the $\mathrm{BDI}$ score has not been demonstrated to be responsive to intervention, this study explored its use to assess change in dyspnoea. Although the tiotropium BDI score did improve compared with placebo treatment, this was not statistically significant (the study was not powered to detect such a change). In this study, patients with milder COPD experienced only a minor degree of baseline activity-related dyspnoea, with BDI scores of 8.1 in both groups. The requirement for rescue medication also provides an indication of the degree of dyspnoea, with low overall use. However, patients receiving tiotropium administered fewer doses of rescue salbutamol in all 12 weeks of the study.

An important goal in COPD therapy is to improve patients' HRQL. The majority of these patients with mild COPD showed no impairment in EQ-5D items that may be affected by physical aspects of respiratory disease. However, many patients did experience moderate painfdiscomfort or moderate anxiety or depression, which may indicate that mild COPD does cause impairment. Unlike previous studies, there was no significant difference between the tiotropium and placebo groups in terms of HRQL. This may be because the study was not powered to investigate such differences or due to methodological differences. Here, HRQL was assessed using the generic EQ-5D rather than the disease-specific St George's Respiratory Questionnaire (SGRQ). ${ }^{22}$ As some patients with milder rather than moderate COPD (GOLD guidelines) may not perceive that their illness impairs their day-to-day life, it may be difficult to detect a deterioration or improvement in HRQL using a generic instrument. Perhaps more sensitive questionnaires such as the SGRQ need to be used for this patient cohort, or the study duration may have been too short for any HRQL improvements to reach significance. Indeed, patients with mild COPD in a post hoc study ${ }^{10}$ had significant improvements in SGRQ total score (by -6.1 units) versus baseline after 1 year.

Given the length of the study, and the nature of the patient population, the absence of significant changes in dyspnoea and HRQL was not unexpected. Nevertheless, we have show $n$ that maintenance treatment in patients with mild

\section{Discussion summary}

\section{a) Difficulties}

A high proportion of participants in this study were not diagnosed with COPD until they were evaluated for study inclusion. Patients with mild COPD who may benefit from interventions, including pharmacotherapy, may not be identified until their disease has progressed and caused further debilitation.

\section{b) Alternative methodologies}

It may have been suitable to assess HRQL using the SGRQ rather than a generic instrument.

\section{c) New questions arising}

Is the beneficial effect of tiotropium on lung function maintained over a study period longer than 12 weeks?

\section{d) Lessons for clinical practice}

Treatment of COPD with tiotropium early in the disease course (GOLD: mild to moderate COPD) improves lung function compared with placebo.

COPD provides tangible benefits in terms of improved lung function. It is possible to speculate on the potential benefits of improved lung function in such patients, particularly if these improvements are maintained over time. For example, improvements in lung function may help patients to retain higher levels of activity for longer. This, in turn, may enable patients to delay entering the vicious cycle of decline whereby reduced activity levels are associated with reduced tolerance and increased levels of dyspnoea.

In conclusion, treatment with tiotropium $18 \mathrm{mcg}$ once daily for 12 weeks improved $\mathrm{FEV}_{1}$ and FVC, compared with placebo, in patients with mild COPD according to the Swedish guidelines (mild to moderate COPD according to the GOLD guidelines). These results suggest that tiotropium is also beneficial in patients with milder COPD, as well as in those with moderate to severe disease. Further longitudinal studies are required to confirm the clinical relevance of these findings.

\section{Acknow ledgements}

The authors acknowledge the provision of editorial support from PAREXEL M MS.

\section{Funding}

Financial support was provided by Boehringer Ingelheim (Stockholm, Sweden) and Pfizer (Täby, Sweden).

\section{Investigators}

The study group is made up of the following investigators located in Sweden: $V$ Agrenius (Stockholm); I Andersson (Alvesta); J Bjerkland (Kalmar); K Boér (Stockholm); D Curiac (Göteborg); P Hellke (Göteborg); R Ivarsson Walther (Linköping); G Johansson (Uppsala); K Karlsen (Stugun); G Kolmodin (Ulricehamn); A 
Lindberg (Luleå and Boden); M Lundgren (Luleå); P M ontneméry (Lund); E Onkamo (Sundsvall); B-A Paradis (Kristianstad); E Pilman (Helsingborg); K Romberg (Höllviken); J Romot (Sunne); G Stratelis (Motala); K Strömberg (Stockholm); B-O Tengmark (Jakobsberg); B Tilling (Åtvidaberg); T Ulvatne (Gislaved); C-E Voss (Helsingborg); P-O Wernersson (Karlstad); N Wigren (Dalum).

\section{References}

1. Rennard S, Decramer M, Calverley PMA, et al. Impact of COPD in North America and Europe in 2000: subjects' perspective of Confronting COPD International Survey. Eur Respir J 2002;20:799-805.

2. Lindberg A, Bjerg-Bäcklund A, Rönmark E, Larsson L-G, Lundbäck B. Prevalence and underdiagnosis of COPD by disease severity and the attributable fraction of smoking Report from the Obstructive Lung Disease in Northern Sweden Studies. Respir Med 2006;100:264-72.

3. Rabe KF, Hurd S, Anzueto A, et al. Global Initiative for Chronic Obstructive Pulmonary Disease. Global strategy for the diagnosis, management, and prevention of chronic obstructive pulmonary disease: GOLD executive summary. Am J Respir Crit Care Med 2007;176:532-55

4. Decramer M, Gosselink R, Rutten-van Mölken M, et al. Assessment of progression of COPD: report of a workshop held in Leuven, 11-12 M arch 2004. Thorax 2005;60:335-42.

5. Vincken W, van Noord JA, Greefhorst APM, et al. Improved health outcomes in patients with COPD during 1 yr's treatment with tiotropium. Eur Respir J 2002;19:209-16.

6. Brusasco V, Hodder R, Miravitlles M, Korducki L, Towse L, Kesten S. Health outcomes following treatment for six months with once daily tiotropium compared with twice daily salmeterol in patients with COPD. Thorax 2003;58:399-404.

7. Casaburi R, Mahler DA, Jones PW, et al. A long-term evaluation of once-daily inhaled tiotropium in chronic obstructive pulmonary disease. Eur Respir If 2002;19:217-24

8. Maltais $F$, Hamilton A, Marciniuk D, et al. Improvements in symptom-limited exercise performance over $8 \mathrm{~h}$ with once-daily tiotropium in patients with COPD. Chest 2005;128:1168-78.

9. Niew oehner DE, Rice K, Cote C, et al. Prevention of exacerbations of chronic obstructive pulmonary disease with tiotropium, a once-daily inhaled anticholinergic bronchodilator: a randomized trial. Ann Intern Med 2005; 143:317-26.
10. Adams SG, Anzueto A, Briggs DD, Jr., Menjoge SS, Kesten S. Tiotropium in COPD patients not previously receiving maintenance respiratory medications. Respir Med 2006;100:1495-1503.

11. The Swedish Society of Respiratory M edicine. Nationellt vårdprogram för KOL. Available at: www.slmf.se/kol/. Accessed 22 November, 2006.

12. Anon. BTS guidelines for the management of chronic obstructive pulmonary disease. The COPD Guidelines Group of the Standards of Care Committee of the BTS. Thorax 1997;52:1-28.

13. American Thoracic Society. Definitions, epidemiology, pathophysiology, diagnosis, and staging. Am J Respir Crit Care Med 1995;152:S78-S120.

14. Swedish Society for Respiratory Medicine. Nationellt vårdprogram för KOL Kroniskt Obstruktiv Lungsjukdom version 1.5 2006. Available at: http://www.slmf.se/kol/.

15. American Thoracic Society. Standardization of spirometry: 1994 update. Am J Respir Crit Care Med 1995;152:1107-36.

16. Quanjer PH, Tammeling GJ, Cotes JE, Pedersen OF, Peslin R, Yernault J-C. Lung volumes and forced ventilatory flows. Report Working Party Standardization of Lung Function Tests, European Community for Steel and Coal. Official Statement of the European Respiratory Society. Eur Respir J Suppl 1993;16:540.

17. Mahler DA, Weinberg DH, Wells CK, Feinstein AR. The measurement of dyspnea. Contents, interobserver agreement, and physiologic correlates of two new clinical indexes. Chest 1984;85:751-8.

18. Fletcher CM, Elmes PC, Fairbain AS. The significance of respiratory symptoms and diagnosis of chronic bronchitis in working population. BMJ 1959;2:25766.

19. Anon. EuroQol-a new facility for the measurement of health-related quality of dife, The Euroo of Group. Health Policy 1990;16:199-208.

20. Rutten-vàn Mölken MP, Oostenbrink JB, Tashkin DP, Burkhart D, Monz BU. Dóesquality of life of COPD patients as measured by the generic EuroQol fivedimension questionnaire differentiate between COPD severity stages? Chest 2006;130:1117-28.

21. Beeh KM, Beier J, Buhl R, Stark-Lorenzen P, Gerken F, Metzdorf N. Efficacy of tiotropium bromide (Spiriva) in patients with chronic-obstructive pulmonary disease (COPD) of different severities. Pneumologie 2006;60:341-6.

22. Jones PW, Quirk FH, Baveystock CM, Littlejohns P. A self-complete measure of health status for chronic airflow limitation. The St George's Respiratory Questionnaire. Am Rev Respir Dis 1992;145:1321-7.

\section{Available online at http://w w w.thepcrj.org}

